\section{MOUNTAIN BLUEBIRD AMPUTEE}

K. MORCK, 424 - 16th St. N.W., Calgary, Alberta. T2N 2C1

The excitement of finding a bird's nest full of eggs does not lose its thrill over the years.

When it is a pair of Mountain Bluebirds, with their exquisite blue dress, that have taken possession of a recently erected bird house, and have built a nest and filled the cup with eight pale blue eggs, the thrill and excitement burst forth anew once again. Perhaps it is seeing the promise of new life to come wrapped up in a tiny egg a new hope, and the procreation of the species.

During the feeding and attending to the young in the nest box, the male bluebird unintentionally drew attention to itself by a continual but intermittent flirting of its wings when perched on a nearby branch with food in its beak for the young. The stump of one leg could sometimes be seen hanging beneath the perching branch. The foot and the lower part of the leg were missing. It had great difficulty perching, usually resting its body low over its good leg on the branch, and sometimes was seen to slide down the branch slightly, and this occasioned the flirting of the wings. It also had great difficulty entering the nest box, and made several attempts before succeeding. (Balance was poor and it could not catch a hold at the hole with the good foot and leg). It had even a greater difficulty getting out of the box after feeding the young. Its head was seen to pop up and down several times inside the hole before it finally succeeded in getting out. On occasion I opened the door and let him out. This box was in a very shaded area along a road clearance rarely used, with high grass grown up along it and with aspen poplars and low shrubbery all around at a little distance in front but close at the back of the tree on which the box had been placed.

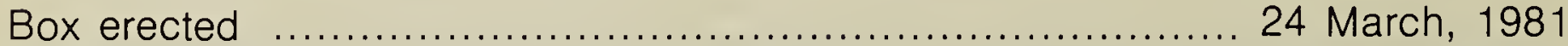

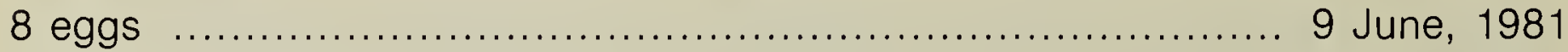

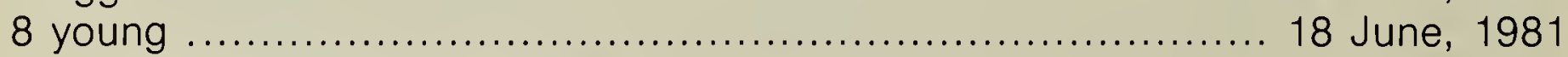
Nest vacated by last young one ............................. 2 July, 1981*

* Four feathered young found dead in the nest, mixed up with the nesting material when I cleaned it out.

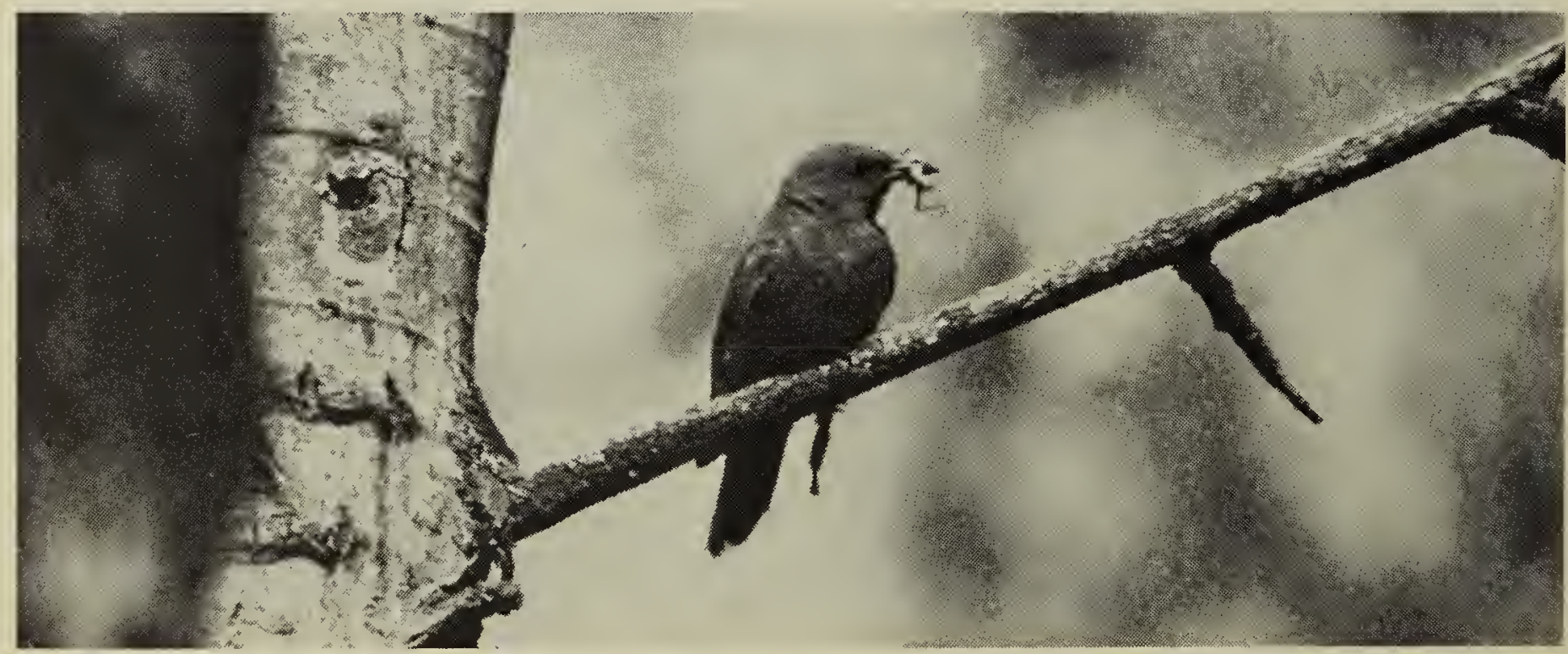

